\title{
Different variations in methods and materials used in tympanoplasty
}

\begin{abstract}
Abbreviations: CST, cartilage shield tympanoplasty; IS, incudo-stapedial

\section{Mini review}

Tympanoplasty or myringoplasty is one of the most commonly Performed procedures by otologists. With advancement in the field of Otology, we have witnessed and been a part of paradigm shift in different methods of tympanoplasty, especially use of various grafting materials in different fashions to obtain maximum success rates in the form of graft acceptance and hearing improvement.
\end{abstract}

Post auricular skin incision remains the most widely used approach for repair of tympanic membrane perforations. Some otologists use End-aural or Endo-meatal incisions for tympanoplasty. There are different methods of canal wall incisions to reach the area, including vascular strip incision, full cuff or near full cuff incision or meatotomy incision. ${ }^{1}$ Granulations and canal wall sagging are some annoying problems in the post operative time in some patients. Some surgeons prefer not to use any canal wall skin incisions. ${ }^{2}$ Various methods of tucking or supporting the graft material are used by different surgeons. Anterior tucking, lateral tucking, circumferential subannular grafting, Over-under method of grafting, 3 flap tympanoplasty, inferior flap tympanoplasty are some of the techniques utilized by many renowned otologists across the globe. ${ }^{3-7}$

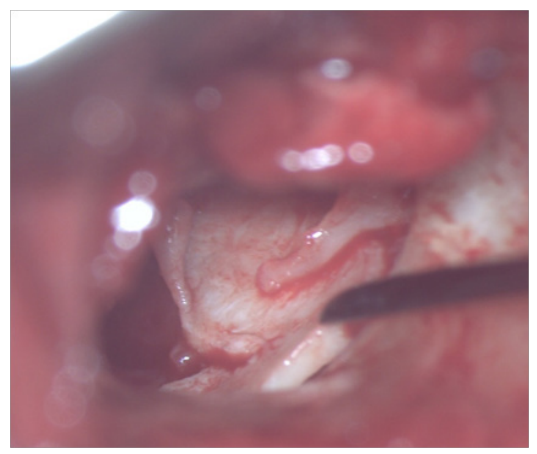

Figure I Cartilage graft being placed medial to handle of malleus

Many materials for grafting have been used for repair of tympanic membrane, including cadaveric dura, vein graft, fascia lata, temporalis fascia, fat graft for small perforations etc. Long term stability of fascia grafts has been a concern over last 2 decades, ${ }^{8}$ so cartilage has been selected as a material that provides stability with better acceptance rates without compromising hearing outcomes. ${ }^{9}$ There are various ways in which cartilage can be used in tympanoplasty. Pallisade method includes using 3 or 4 smaller pieces of cartilage arranged in a shape that will provide a stable structure to repair ear drum perforation. ${ }^{10}$ Cartilage island flap method used in many surgeries includes keeping perichondrium attached to the cartilage piece on one side and removing a vertical strip of cartilage in the middle of the piece to accomodate the handle of malleus.

Cartilage shield tympanoplasty (CST) has been described and used in recent times with good success rates. ${ }^{11,12}$ The technique uses a piece of tragal or conchal cartilage from ear as grafting material and making
Volume 10 Issue 6 - 2018

\author{
Sohil Vadiya \\ Consultant ENT Surgeon, HCG Hospital, India
}

Correspondence: Sohil Vadiya, Consultant ENT Surgeon, HCG Hospital, India, Ellisbridge, Ahmedabad, India-380006, India, Tel +919925273533, Email sohelv8I@gmail.com

Received: March 31, 2018 | Published: November 19, 2018

a notch in its superior aspect to accomodate handle of malleus. Modified version of CST would avoid making a notch and putting the cartilage piece directly lateral to incudo-stapedial (IS) joint, medial to handle of malleus and supporting the graft from medial side by gelfoam pieces (Figure 1). ${ }^{13}$ Temporalis fascia can also be used in combination with cartilage piece.

Thickness of the cartilage piece also has been a concern for tympanoplasty. Slicing the cartilage piece before grafting has been used with good success. ${ }^{14}$ Full thickness cartilage grafting also yields good results if properly placed..$^{15}$

Therefore, in tympanoplasty, we can use any of the different canal wall skin incisions, in combination with fascia or cartilage or both in the form of a composite graft as grafting material with any of the supporting techniques like lateral tucking or anterior tucking. Good skill development under supervision and experience with time brings out the best otology practice and superior results.

\section{Acknowledgments}

None.

\section{Conflict of interest}

The author declares there is no conflict of interest.

\section{References}

1. Vadiya SI, Shah SK, Chaudhary M. Comparison of canal wall incisions for tympanoplasty for large central perforations. Indian Journal of Otology. 2015;21(3):186-189.

2. Gérard JM, el Makhloufi K, Gersdorff M. Tympanoplasty without skin incision of the external auditory canal: Preliminary results. Acta Otorhinolaryngol Belg. 2003;57(3):183-185.

3. Mokhtarinejad F, Okhovat SA, Barzegar F. Surgical and hearing results of the circumferential subannular grafting technique in tympanoplasty: A randomized clinical study. Am J Otolaryngol. 2012;33(1):75-79.

4. Vadiya S. Concept, importance and practice of lateral tucking in tympanoplasty. Indian J Otolaryngol Head Neck Surg. 2017;69(4):480 482.

5. Kartush JM, Michaelides EM, Becvarovski Z, et al. Over-under tympanoplasty. Laryngoscope. 2002;112(5):802-807.

6. Roychaudhuri BK. 3-flap tympanoplasty-A simple and sure success technique. Indian J Otolaryngol Head Neck Surg. 2004:56(3):196-200. 
7. Gavriel H, Eviatar E. Inferior flap tympanoplasty: a novel technique for anterior perforation closure. Biomed Res Int. 2013;2013:758598.

8. Indorewala S. Dimensional stability of the free fascia grafts: An animal experiment. Laryngoscope. 2002;112(4):727-730.

9. Dornhoffer J. Cartilage tympanoplasty: Indications, techniques, and outcomes in a 1,000 patient series. Laryngoscope. 2003;113(11):18441856.

10. Neumann A, Kevenhoerster K, Gostian AO. Long term results of palisade cartilage tympanoplasty. Otol Neurotol. 2010;31(6):936-939.

11. Duckert LG, Muller J, Makielski KH, et al. Composite autograft "shield" reconstruction of remnant tympanic membranes. Am J Otol. 1995;16(1):21-26.
12. Athanasiadis A, Sismanis. Tympanoplasty: Tympanic Membrane Repair. In: Gulya AJ, Minor LB, Poe DS, editors. People's medical publishing house -USA: Glasscock-Shambaugh Surgery of the Ear. 6th ed. 2010. p. 478-482.

13. Vadiya SI. Technique and results of cartilage shield tympanoplasty. Indian Journal of Otology. 2014;20(4):196-198.

14. Mukbel KM, Thabet ESM. Repair of subtotal tympanic membrane perforation by ultrathin cartilage shield: evaluation of take rate and hearing result. Eur Arch Otorhinolaryngol. 2013;270(1):33-36.

15. Vadiya S, Bhatt S. Comparison of partial thickness and full thickness tragal cartilage graft during modified cartilage shield tympanoplasty for type I procedures. Indian J Otolaryngol Head Neck Surg. 2016;68(1):30-33. 